\title{
Die voorkoms van lewenstylverwante koronêre risikofaktore by Suid-Afrikaanse bestuurslui
}

\author{
L.I. Dreyer, G.L. Strydom \& S. van der Merwe \\ Departement Menslike Bewegingskunde \\ Potchefstroomse Universiteit vir $\mathrm{CHO}$ \\ POTCHEFSTROOM
}

\begin{abstract}
The presence of lifestyle related coronary risk factors among South African business executives

The general health status of an employee often displays a direct relationship with his productivity. This phenomenon, to a large extent, initiated the trend in several companies to provide the so-called "employeesupporter programmes" which concentrate on a holistic approach towards tolal well-being. The lifestyle of the South African executive is to a large extent destructive of health and total well-being. In many cases this leads to premature retirement, serious illnesses and even death.

Executives (388) of 20 companies representing the mining, steel, construction, financial and motor industry, were evaluated for the purpose of

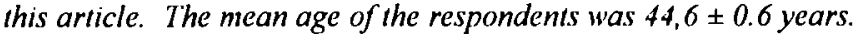

In $74,3 \%$ of the cases a low physical working capacity was found $<2,5$ Watr $\mathrm{kg}^{-1}$ ). while $4,6 \%$ of the executives showed a percentage body fat of $220 \%$ which is regarded as a coronary risk factor. In $38.7 \%$ and $58,2 \%$ of the cases elevated systolic and diastolic blood pressure values were respectively found. The following amount of respondents showed elevated values with regard to the biochemical parameters: total cholesterol $(69,5 \%)$, low density lipoprotein cholesterol $(64,8 \%)$, triglycerides $(24,1 \%)$ and total cholesterol/HDL ratio (77,0\%). In $42,2 \%$ of the cases an abnormally low level of high density lipoprotein was found.
\end{abstract}

Key words: Executive fitness, coronary risk factors

\section{Inleiding}

Ons leef volgens Louw (1992) in 'n pragmatiese eeu waar die doen-kwaliteite en kennis-kwaliteite van 'n persoon swaarder weeg as sy wees-kwaliteite. Identiteit word gevolglik nie meer bepaal deur wie jy is nie maar deur wat jy doen, hoeveel jy weet, hoe hoog jou inkomste is en watter prestasies jy lewer. 
Die voorkoms van lewenstylverwante koronêre risikofaktore by Suid-Afrikaanse bestuurslui

Wanneer 'n tema wat handel oor lewenstyl, gesondheid en liggaamlike versorging dus vanuit 'n Christelike perspektief belig word, moet rekening gehou word met bogenoemde wisselwerking wat tussen die oorheersende waardes van ons hedendaagse kultuursituasie en die identiteitsoeke van die mens bestaan. Die veranderde demografiese, sosiale, ekonomiese en politieke karakter van ons samelewing is volgens navorsers (Bellingham et al., 1989; Sweeting, 1990) by uitstek daarvoor verantwoordelik dat die mens op geestelike gebied nie meer vaste steunpunte het nie. Die klem wat die moderne samelewing op aspekte soos individualisme, prestasie, onafhanklikheid en selfhandhawing plaas, lei volgens Bellingham et al. (1989) tot die verbrokkeling van familiebande en sosiale ondersteuningsnetwerke. Dit lei tot onsekerhede, gevoelens van magteloosheid en hulpeloosheid asook tot selfverwaarlosing, alkoholisme, dwelmverslawing, depressie, vereensaming en spanning.

Risikofaktor-identifisering en gesondheidsverwante inligting is dus duidelik nie genoeg om langtermynlewenstylverandering teweeg te bring nie. In dié verband maak Sweeting (1990) die volgende opmerking: "One of the most clearly established findings of health education research is that health-related information is rarely sufficient to initiate or maintain health-related practices".

Sweeting (1990) wys daarop dat gedrag, ingesteldhede en waardes direk teruggevoer kan word na die manier waarop iemand homself sien en wat hy graag wil bereik. Die beeld wat die persoon van homself het, word volgens Eagleton (1992) bepaal deur dit wat die persoon van homself dink, deur dit wat ander van hom dink, maar veral deur dit wat die persoon dink ander van hom dink en verwag. Die mens wat beheer word deur dit wat hy dink ander van hom dink en verwag, het volgens Eagleton (1992) 'n intense vrees vir verwerping. So 'n persoon vrees dat hy nie volgens die verwagtinge van mense sal presteer nie en dit beteken vir hom totale verwerping. Hierdie ingesteldheid is in Bybelse sin afgodery. 'n Afgod is enige-iets of iemand wat in die plek van God gedien word.

Dit is bekend dat Suid-Afrikaanse bestuurslui veral geneig is om hulself ter wille van werkprestasie te verwaarloos (Uys \& Coetzee, 1989). Persoonlike verwaarlosing word ook deur menige bestuurder gesien as die prys wat vir sukses betaal moet word. Hierdie ingesteldheid spruit volgens Uys en Coetzee (1989) voort uit die intense vrees wat bestuurslui het vir mislukking en die verleentheid wat daarmee gepaard gaan.

Bestuurslui beland dus in 'n proses waar hulle beheer verloor oor hulle waardes, norme, beginsels en standaarde wat die raamwerk is waarin 'n persoonlike behoudende lewenstyl gesetel is. In genoemde ondersoek van Uys en Coetzee (1989) is bevind dat slegs $15,9 \%$ van Suid-Afrikaanse bestuurslui hulle verhouding met hulle Skepper as besonder goed beskou terwyl meer as $57 \%$ dit 
as redelik en swak beskou het. Verder het $38,8 \%$ van die bestuurders aangedui dat hulle geen kerk besoek nie en 47,7\% dat hulle nie Bybel lees en bid nie.

Navorsers soos Bellingham et al. (1989), Sweeting (1990) en Dreyer (1995) is oor die algemeen van mening dat die geestelike dimensie van gesondheid die hoeksteen van gedrag vorm. Die geestelike dimensie van gesondheid verwys na die kwaliteit van die persoon se verhouding met sy God asook na die mate waartoe die persoon in kontak met sy waardes en norme is (Bellingham et al., 1989; Dreyer, 1995).

Godsdienstige aktiwiteite soos erediens, belydenis, gebede en lofsegging wat op eksplisiete en gekonsentreerde wyse op God fokus, is volgens Van der Walt (1992) nie die enigste religieuse aktiwiteite van die mens nie. Die mens se lewe in sy totaliteit is antwoord op God se Woord, aldus Van der Walt (1992). Jou beroep of werkprestasie is dus nie belangriker as liggaamlike instandhouding nie - net soos preek nie belangriker as handeldryf is nie en gebed nie vromer en belangriker as kinders grootmaak is nie

Die doel van hierdie artikel is om die resultate van 'n studie wat die voorkoms van lewenstylverwante koronêre risikofaktore by 'n groep Suid-Afrikaanse bestuurslui bestudeer het te bespreek. Dit kan ' $n$ aanduiding gee of daar 'n behoefte aan lewenstylintervensie- en veral geestelike verrykingsprogramme by bestuurslui bestaan. In Bybelse terme is liggaamlike verwaarlosing ter wille van werkprestasie onaanvaarbaar. Die mens het nie (bykomend tot sy menswees) 'n religieuse roeping nie; sy hele bestaan - insluitend die manier hoe hy sy liggaam versorg - is diens aan God of 'n afgod. "Of weet julle nie dat julle liggaam 'n tempel is van die Heillige Gees wat in julle is ... en dat julle nie aan julleself behoort nie? Want julle is duur gekoop. Verheerlik God dan in julle liggaam en julle gees wat aan God behoort" (1 Kor. 6:19, 20).

\section{Metode}

In die ondersoek waanna reeds verwys is, is 388 bestuurders uit 20 verskillende maatskappye (myn-, diamant-, platina-, staal-, konstruksie-, finansiële en die waterbedryf) betrek. Die gemiddelde ouderdoin van die groep was 44,6 $\pm 0,6$ jaar.

Alle respondente wat medikasie gebruik het wat hulle bloeddruk, harttempo en biochemiese waardes kon beinvloed se gegewens is nie in die studie gebruik nie Persoonlike inligting oor aspekte soos ouderdom en lewensgewoontes soos rook, deelname aan fisieke aktiwiteit en drankverbruik is met behulp van 'n vraelys bepaal.

Die arteriële bloeddruk is met behulp van 'n kwikkolomsfigmomanometer oor die 
Die voorkoms van lewenstylverwante koronêre rısikofakıore by Suid-Afrikaanse bestunrslui

brachiale pols van die regterann geneem. Tydens die neem van die sistoliese en diastoliese bloeddruklesings is gebruik gemaak van die eerste en vierde Korotkoff-klanke (Meyer \& Meyer, 1988). Daar is ook seker gemaak dat die respondente rustig, ontspanne en op hulle gemak was ten einde die bloeddruklesings so betroubaar as moontlik te maak. Twee bloeddruklesings is geneem en indien die lesings meer as $5 \mathrm{mmHg}$ val mekaar verskil het, is die respondent vir 'n verdere 5 tot 10 minute laat rus, waarna die twee lesings weer geneem is. Die gemiddeld van die laaste twee lesings is dan genoteer - mits dit minder as 5 $\mathrm{mmHg}$ van mekaar verskil het

Elke respondent se persentasie liggaamsvet is ook bepaal deur die volgende velvoue te meet, naamlik triceps, subscapula, supra-iliac, para-umbilicus, quadriceps en mediale kuit. Die volgende formule is vir die berekening van die persentasie liggaamsvet gebruik, naamlik:

Persentasie liggaamsvet $=($ som van 6 velvoue $\times 0,1051)+2,585($ Carter, 1982$)$.

Laastens is daar ook op elke respondent 'n submaksimale meervlakkige fisieke werkvermoëtoets $\left(F W_{170}\right)$ gedoen deur van 'n monark-fietsergometer gebruik te maak (Denolin et al., 1967). Bloeddruk-, harttempo- en EKG-registrasie is geneem na elke werkvlak, wat 5 minute geduur het. Die toets is gestaak sodra die respondent ongeveer $70 \%-80 \%$ van sy ouderdomsaangepaste maksimale harttempo bereik het en mits daar nie vooraf enige aanduidings vir die beëindiging van die toets ontstaan het nie (ACSM, 1986). Elke respondent is ook op 'n deurlopende basis gemonitor met behulp van die outomatiese monitorfasiliteit van die "Hellige EK41" EKG-apparaat.

Die volgende biochemiese ontledings is op die bloedserum na 'n vasperiode van 12 uur gedoen: totale cholesterolkonsentrasie, hoë en lae digtheidslipoproteien en trigliseriedkonsentrasie. Die analises is deur ' $n$ bekende patologielaboratorium gedoen deur van die ensiematiese metode gebruik te maak.

Al die gegewens is verwerk deur gebruik te mak van die Statistica dataverwerkingspakket wat op die $\mathrm{PU}$ vir $\mathrm{CHO}$ se netwerk beskikbaar is.

\section{Resultate en bespreking}

Volgens Jones en Campbell (1982) kan 2,5 watt kg-1 as 'n gemiddelde fisieke werkvermoe ${ }_{170}\left(\mathrm{FWV}_{170}\right)$ vir volwasse mans aanvaar word. Uit Tabel 1 blyk dit dat slegs $25,7 \%$ van die bestuurders wat in die studie geëvalueer is, 'n FWV 170 van $>2,5$ watt $\mathrm{kg}^{-1}$ vertoon. 'n Laer as normale $F W V_{170}\left(<2,5\right.$ watt kg $\left.{ }^{-1}\right)$ kom dus by $74,3 \%$ van hierdie korps bestuurders voor. 'n Verlaagde deelname aan fisieke aktiwiteit gedurende vryetyd as gevolg van 'n gebrek aan tyd is moontlik die rede hiervoor (Dreyer et al., 1988). 
Uys en Coetzee (1989) toon aan dat die Suid-Afrikaanse uitvoerende amptenaar as gevolg van werkbeheptheid en die dominerende invloed van die werkslas homself en sy gesin verwaarloos. Gesondheid, die gesin, sosiale interaksie asook sport en ontspanning word deur die oorgrote meerderheid bestuurslui in die studie van Uys en Coetzee (1989) heelwat laer op 'n prioriteitslys geplaas as hul werk. Uys en Coetzee (1989) wys daarop dat dit ironies is dat 'n standpunt soos "cowboys don't cry" of selfverwaarlosing ter wille van werkprestasie juis die teenoorgestelde resultate tot gevolg het. Fisieke onaktiwiteit is reeds as aanleidende oorsaak uitgewys in 'n verskeidenheid hipokinetiese siektetoestande (Kraus \& Raab, 1961). Hierdie siektetoestande kan nie net vir die individu

- ongesteldheid beteken nie maar kan ook sy werksproduksie benadeel. 'n Goeie fisieke toestand is derhalwe vir die uitvoerende amptenaar noodsaaklik om die groot werklas optimaal te hanteer (Uys \& Coetzee, 1989).

Wanneer na die voorkoms van koronêre risikofaktore by uitvoerende amptenare gekyk word, blyk dit uit Tabel 1 dat 95,4\% van die respondente 'n persentasie liggaamsvet het van minder as $20 \%(\bar{x}=12,9 \%)$, wat deur Pollock et al. (1978) as binne die normale grense beskou word. Die oorblywende $4,6 \%$ se gemiddelde persentasie liggaamsvet was $23,3 \%$ - respondente dus met 'n verhoogde persentasie liggaamsvet. Anderson en Jose (1987) toon in dié verband dat werkers wat 'n ernstige probleem ten opsigte van obesiteit het, 'n $48 \%$ groter kans staan om mediese eise wat $\$ 5000$ per jaar oorskry, in te dien. Brownnell et al. (1984) vind dat elke $1 \%$ afname in persentasie liggaamsvet by obese individue geassosieer kan word met ' $n$ verhoging van $\$ 2.93$ in koste-effektiwiteit per werknemer van die maatskappy.

Ten opsigte van hipertensie blyk dit dat $38,7 \%$ en $58,2 \%$ van die respondente onderskeidelik sistoliese en diastoliese bloeddrukwaardes vertoon wat hoër is as die aanvaarde waardes vir normale bloeddruk, naamlik $>140 \mathrm{mmHg}$-sistolies (Brooks \& Fahey, 1984) en <90 mmHg-diastolies (Lamb, 1984; Moir, 1989). Hipertensie is 'n primêre risikofaktor vir koronêre hartsiekte (Brooks \& Fahey, 1984; Paffenbarger, 1985), kardiovaskulêre siektes (Egan \& Schmouder, 1988; Weiss, 1988), kongestiewe hartsiektes (Wenger, 1988) en nierversaking (Bedworth \& Bedworth, 1982). Volgens die Society of Actuaries and Associations of Life Insurance Medical Directors of America (1979) neem die risiko vir vroeë ongeskiktheid met $160 \%$ toe by persone met sistoliese en diastoliese waardes van hoër as $147 \mathrm{mmHg}$ en $87 \mathrm{mmHg}$ onderskeidelik. Dit spreek dus vanself dat hierdie risikofaktor wat relatief volop by die korps van uitvoerende amptenare in Suid-Afrika voorkom, besonder ernstige implikasies vir 'n maatskappy kan inhou. Op grond van die uitwerking wat die gebruik van hipertensiemedikasie op werkafwesighede (ongesteldheid en doktersbesoeke) sowel as op die werker se algemene gevoel van welstand kan hê, word bereken 
dat ' $n$ werker wat hipertensief is, sy werkgewer in die orde van $\$ 500$ per jaar kan kos (Cooper, 1987)

'n Verband is ook alreeds deur verskeie epidemiologiese studies tussen die voorkoms van aterosklerotiese hartsiektes en verhoogde totale cholesterol- (TC), trigliseried- (TG), LDL-cholesterol-, TC/HDL-verhouding asook verlaagde HDLcholesterolkonsentrasie aangetoon (Byrne, 1991; Gordon \& Gibbons, 1991).

Dit blyk dat totale cholesterolkonsentrasie 'n positiewe reglynige verband met die voorkoms van koronêre hartsiektes vertoon vanaf 'n waarde van 5,2 mmol. $\mathrm{l}^{-1}$ (Stamler et al., 1986). Byme (1991) wys verder daarop dat sodra LDLcholesterolkonsentrasie styg tot bokant 'n waarde van $3,4 \mathrm{mmol}^{-1}$, die aterosklerotiese proses 'n aanvang begin neem. Ten opsigte van trigliseriedkonsentrasie toon Cooper (1988) aan dat 'n waarde van hoër as $2,3 \mathrm{mmol} \mathrm{I}^{-1}$ as 'n koronêre risikofaktor beskou kan word. Uit die literatuur blyk dit dat HDLcholesterolkonsentrasie 'n bepaalde beskermende effek teen die ontwikkeling van KHS toon (Miller \& Miller, 1975). Hoe hoër die HDL-cholesterolkonsentrasie, hoe laer blyk die risiko te wees (Cooper, 1988; Byrne, 1991). 'n Waarde van laer as $0,9 \mathrm{mmol}^{-1}$ kan volgens Byrne (1991) as 'n verlaagde waarde by HDLcholesterolkonsentrasie beskou word. Volgens 'n studie van Antzenius et al. (1985) op pasiënte wat reeds koronêre hartsiekte het, korreleer die TC/HDLverhouding van al die bekende koronêre risikofaktore die beste met angiogrambepaalde-progressie van aterosklerotiese hartvatsiekte. Hierdie verhouding moet volgens Cooper (1988) laer as 4,6 wees.

By $69,5 \%$ van die respondente het 'n verhoogde totale cholesterolkonsentrasie voorgekom, terwyl in $64,8 \%$ en $42,2 \%$ van die gevalle die LDL-cholesterol- en HDL-cholesterolwaardes respektiewelik verhoog en verlaag was. Wanneer die TC/HDL-verhouding bereken word - 'n verhouding wat allerweë beskou word as van die betekenisvolste aanduidings van die risiko om koronêre hartsiekte te ontwikkel (Brooks \& Fahey, 1984), vertoon 77\% van die respondente 'n abnonnale waarde. Uit die resultate is dit duidelik dat 'n groot persentasie van die korps van hoogs opgeleide mannekrag in Suid-Afrika 'n hoë risiko loop om vanweë die ongunstige lipiedbeeld wat hulle vertoon, vroeër of later in hulle lewe koronêre hartsiekte te ontwikkel.

Die voorkoms van bogenoemde risikofaktore by die Suid-Afrikaanse uitvoerende amptenaar word in Tabel 1 aangetoon.

Sigaretrook, hipertensie en totale cholesterol word tans beskou as die drie primêre risikofaktore vir die ontwikkeling van koronêre hartsiektes. Uit Figuur 1 blyk dit dat slegs 3\% van die bestuurslui wat in die studie geëvalueer is, geeneen van die genoemde risikofaktore vertoon nie, terwyl onderskeidelik $25 \%, 43 \%$ en $29 \%$ een, twee en al drie van die primêre risikofaktore vertoon. Gebasecr op die 


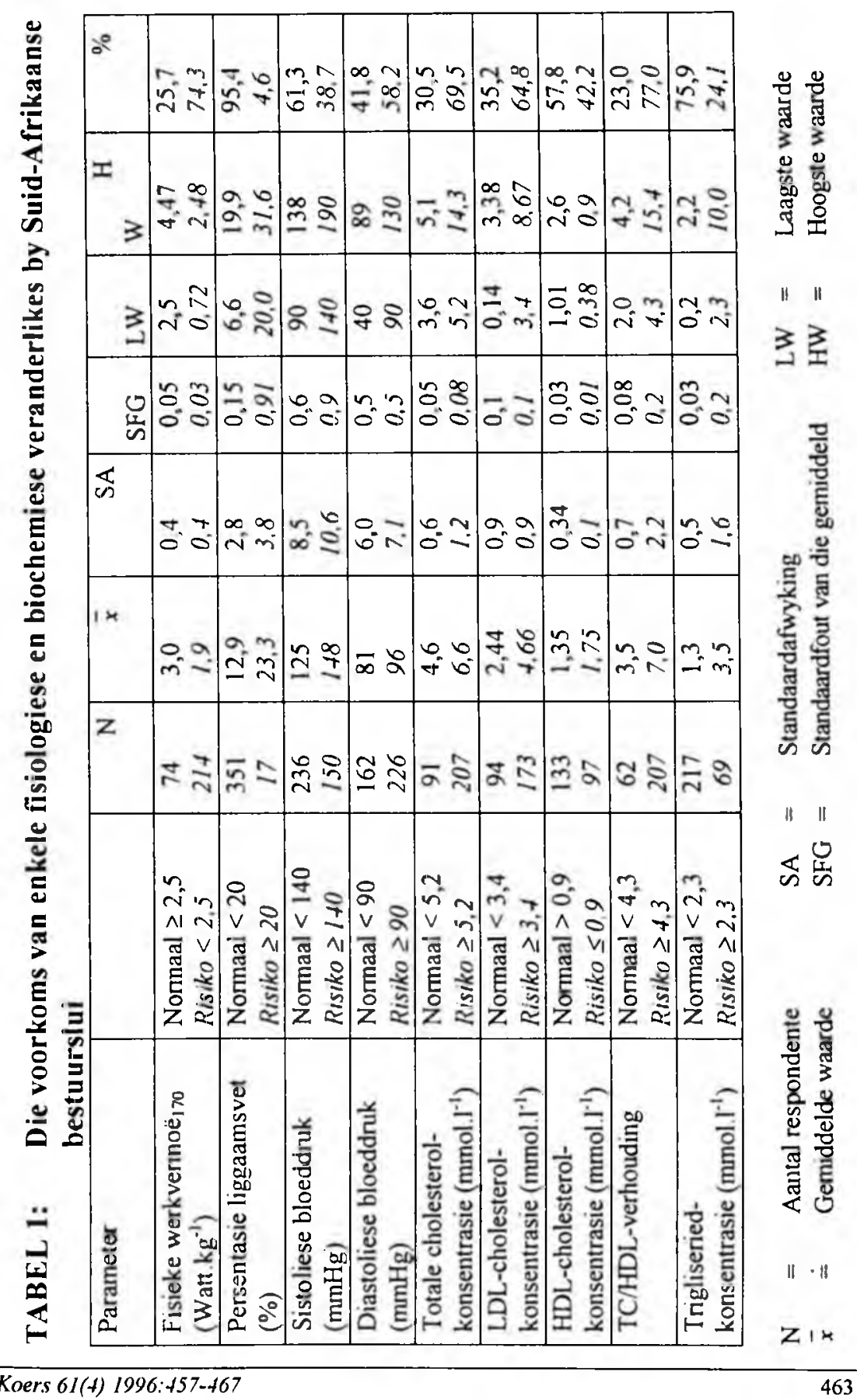


Die voorkoms van lewenstylvenwante koromêre risikofaktore by Swid-Afrikaanse bestuntshiu

resultate van die Framingham-studie toon Pollock et al. (1978) aan dat wanneer meer as een van die primêre risikofaktore by 'n individu voorkom, so 'n individu se risiko vir KHS kumulatief verhoog.

Barlow et al. (1990) toon aan dat 'n verhoogde vlak van kardiorespiratoriese fiksheid beskerming teen koronêre mortaliteit kan bied selfs wanneer die drie primêre koronêre risikofaktore, naamlik sigaretrook, verhoogde sistoliese bloeddruk en verhoogde totale cholesterolkonsentrasie aanwesig is. Howard en Mikalacki (aangehaal in Cox, 1982) wys verder daarop dat die fisiologiese voordele van gereelde deelname aan fisieke aktiwiteit soos 'n verbeterde kardiorespiratoriese vermoë en verhoogde energievlakke, nie net die werkers se produktiwiteit direk kan beïnvloed nie, maar ook bepaalde psigologiese voordele tot gevolg kan hê. Hierdie voordele kan 'n invloed op werksbevrediging, moreel en houding teenoor werk, kollegas en ondergeskiktes hê. Die uitwerking wat fisieke aktiwiteit en 'n verbeterde kardiorespiratoriese uithouvermoë op die geestesingesteldheid van die werker het, blyk dan ook die meganisme te wees waarvolgens dit gesondheidsorgkoste, personeelomset en kortternynwerkafwesighede positief kan beînvloed (Edington, 1986).

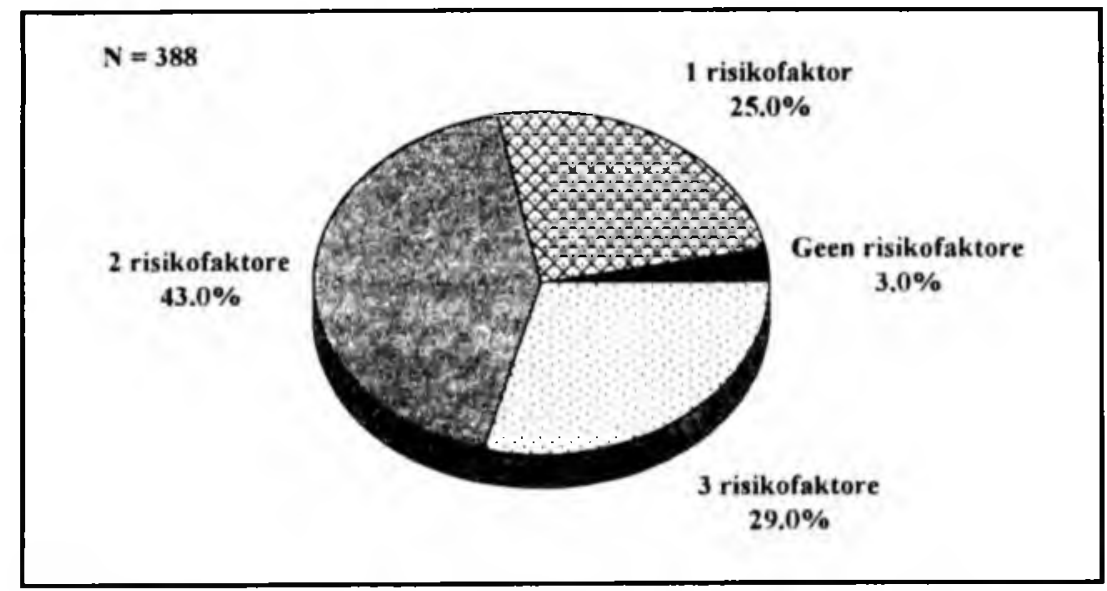

Figuur 1: Die voorkoms van primêre risikofaktore* by Suid-Afrikaanse bestuurslui

* = Hipertensie, verhoogde totale cholesterolkonsentrasie en rook 


\section{Gevolgtrekking}

Uit hierdie resultate blyk dit dat 'n relatief hoë voorkoms van koronêre risikofaktore teenwoordig is by die blanke bestuurslui wat in die ondersoek betrek is. Dit is duidelik dat bepaalde strategieë met betrekking tot personeelontwikkelingsprogramme wat spesifiek toegespits is op die tydige identifisering van koronêre risikofaktore, tesame met intervensieprogramme vir die korps van amptenare deur maatskappye aangebied sal moet word

\section{Aanbeveling}

Uys en Coetzee (1989) het reeds in 1989 aangetoon dat daar by bestuurslui in Suid-Afrika ' $n$ filosofie van selfverwaarlosing bestaan. Hierdie filosofie is in Bybelse terme onaanvaarbaar. Dit is 'n filosofie wat in alle waarskynlikheid teruggevoer kan word na die wisselwerking wat tussen die waardes van die hedendaagse kultuursituasie en die identiteitsoeke van die mens bestaan. Lewenstylintervensieprogramme moet dus nie net op risikofaktor-identifisering en -behandeling fokus nie maar ook op aspekte soos maatskappykultuur, waardes, norme, selfbeeld, lewensinvolheid en geestelike verryking.

\section{Bibliografie \\ ACSM}

$k y k$

AMERICAN COLLEGE OF SPORTS MEDICINE

AMERICAN COLLEGE OF SPORTS MEDICINE. 1986. Guidelines for exercise testing and prescription. 3rd Edition. Philadelphia : Lea \& Febiger 179 p.

ANDERSON, D R.1. \& JOSE, W.S. 1987. Employee lifestyle and the bottom line. Filness in Business, 2:86-91.

ARNTZENIUS, AC., KROMHOUT, D, BARTH, J.D., REIBER, J.H.C., BRUSCHKE, A.V.G., BUIS, B., VAN GENT, C M, KEMPEN-VOOGD, N., STRIKWERDA, S. \& VAN DER VELDER E.A. 1985. Diet lipoproteins, and the progression of coronary atherosclerosis - The Leiden intervention trail. New England Journal of Medicine, $312(13) 804-811$

BARLOW, C.E., BRILL, P.A., BLAIR, S.N. \& KOHL, H.W. 1990. Practical advice on fitness and mortality: A new approach to exercise prescription. American Journal of Health Promotion, 4(5):391-393.

BEDWORTH, A.E. \& BEDWORTH, D A. 1982 Health for human effectiveness New York: Prentice-Hall.

BELLINGHAM, R., COHEN, B , JONES, T. \& SPANIOL, L. 1989. Connectedness: some skills for spiritual health. American Journal of Health Promotion, 4(1): 18-31

BROOKS, GA \& FAHEY, T.D 1984. Exercise physiology, human bioenergetics and its applications. New York: John Wiley \& Sons. $726 \mathrm{p}$.

BROWNWELL, K.D., COHEN, R.G., STUNKARD, A.J., FELIX, M R \& COOLEY, N.B 1984 Weight loss competitions at the worksite: Impact on weight, morale and costeffectiveness. American Journal of Public Heallh, 74:1283-1285.

BYRNE, K P. 1991. Understanding and managing cholesterol: a guide for wellness professionals Champaign : Human Kinetics $334 \mathrm{p}$ 
CARTER, J.E.L. 1982. Body composition of Montreal Olympic athletes. (In Carter, J.EL, ed. Physical structure of Olympic athletes. Part I: The Montreal Olympic Games Anthropometric Project. Basel : Karger. p. 107-166.)

COOPER, K.H. 1987. Health in the workplace. The Aerobics News, 2(5):1-2

COOPER, K.H. 1988. Controlling cholesterol. New York : Bantam. 395 p

COX, M.H. 1982. Corporate investment in human resources: A new twist. The Canadian Business Review: 9-14, Spring.

DENOLIN, H., MESSIN, R. \& DEGRE, S. 1967. Testing for the working capacity of cardiac patients. (In Karvonen, M.J \& Barry, A.J. eds. Physical activity and the heart. Springfield : Charles C. Thomas p. 21-32.)

DREYER, L.I. 1995. Totale welstand - 'n begripsomskrywing. Potchefstroom : Instituut vir Biokinetika, PU vir CHO. 53 p.

DREYER, L.I., STRYDOM, G.L \& MALAN, D D.J 1988. Die fisieke aktiwiteitsprofiel en fisieke werkvermoe van uitvoerende amptenare in enkele geselekteerde Suid-Afrikaanse maatskappye Suid-Afrikaanse Tydskrif vir Navorsing in Sport, Liggaamlike Opvoedkunde en Ontspanning, $11(2): 9-20$.

EAGLETON, H. 1992. Wanneer is ek 'n wenner? Prestasie, prestasiebeheptheid en genade. (In Venster op sport. Potchefstroom : IRS p. 61-75.)

EDNGTON, DW. 1986 Health promotion programs and health-care expenditures. Optimal Health, 2(3):33-34

EGAN, B. \& SCHMOUDER, R. 1988 The importance of hemodynamic considerations in essential hypertension. Part II. The American Heart Journal, 166:594-599.

GORDON, N \& GIBBONS, L. 1991. The complete heart recovery guide. Cape Town Oxford University Press. $479 \mathrm{p}$.

JONES, N.L. \& CAMPBELL, E J.M 1982. Clinical exercise testing. 2nd ed. Philadelphia : Saunders. $268 \mathrm{p}$

KRAUS, H. \& RAAB, W. 1961. Hipokinetic disease: Diseases produced by lack of exercise. Illinois : Charles C. Thomas. $193 \mathrm{p}$.

LAMB, D R. 1984. Physiology of exercise - responses and adaptations. New York : MacMillan. 489 p.

LOUW, D. 1992. Sport in 'n Christelike perspektief. Die sportman as nuwe mens. (In Venster op sport. Potchefstroom : IRS, p 27-38)

MEYER, B.J. \& MEYER, A.C. 1988. Patologie: hipertensie, hartversaking en skok. (In Meyer, B.J. red. Die fisiologiese basis van geneeskunde. Vierde uitgawe. Pretoria : HAUM. p. 40 1-40.14.)

MILLER, G.J. \& MILLER, N.E. 1975. Plasma high-density lipoprotein concentration and development of ischaemic heart disease. Lancel, 4:16-19.

MOIR, T.W. 1989. Nonischemic cardiovascular disease. (In Franklik, B.A., Gordon, S. \& Timmis, G C Exercise in modern medicine. Baltimore : Williams \& Wilkins. p. 195.)

PAFFENBARGER, R.S. 1985. Physical activity as a defense against coronary heart disease. (In Conner, W E. \& Bristow, J.D., eds. Coronary heart disease prevention, complications and treatment Philadelphia: Lippincott. p 135-151.)

POLLOCK, M L., WILLMORE, J.M \& FOX, S.M. 1978. Health and fitness through physical activity. New York : Wiley. $358 \mathrm{p}$.

SOCIETY OF ACTUARIES AND ASSOCIATION OF LIFE INSURANCE MEDICAL DIRECTORS OF AMERICA. 1979. Blood pressure study. USA : Recording \& Statistical 
STAMLER, J, WENTWORTH, D \& NEATON, J 1986. Is relationship between serum cholesterol and risk of premature death from coronary heart disease continuous and graded? Finding in 356222 primary screenees of the Multiple Risk Factor Intervention Trial (MRFIT). Journal of the American Medical Association, 256(20):2823-2828

SWEETING, R L 1990. A value approach to health behavior. Champaign, Ill : Human Kinectics. $251 \mathrm{p}$

UYS, R. \& COETZEE, J.J.L 1989 Selfbestuur en selfinstandhouding by die moderne bestuurder. Potchefstroom : Nagraadse Skool vir Bestuurswese, PU vir CHO.

VAN DER WALT, B. 1992. Christen en sportman/-vrou, Christen of sportman/-vrou, of Christensportman/-vrou. (In Venster op sport Potchefstroom: IRS. p. 13-24.)

WEISS, S.M 1988. Stress management in the treatment of hypertension. Part II. The American Heart Journal, 116:645-649

WENGER, N.K. 1988 Quality of life issues in hypertension: Consequences of diagnoses and considerations in management. The American Heart Journal, 166:628-632. 
